\title{
Temporal-spatial distribution of non-point source pollution in a drinking water source reservoir watershed based on SWAT
}

\author{
MIN WANG ${ }^{1}$, WEN CHENG ${ }^{1}$, BO-SHI YU ${ }^{2}$ \& YONG FANG ${ }^{2}$ \\ 1 State Key Laboratory of Eco-Hydraulic Engineering in Shannxi, Xi'an University of Technology, Xi'an, 710048, China \\ 271781310@qq.com; wencheng@xaut.edu.cn \\ 2 Shaoxing Tang Pu Reservoir Co. Ltd, Shangyu, Zhe Jiang, 312364, China
}

\begin{abstract}
The conservation of drinking water source reservoirs has a close relationship between regional economic development and people's livelihood. Research on the non-point pollution characteristics in its watershed is crucial for reservoir security. Tang Pu Reservoir watershed was selected as the study area. The non-point pollution model of Tang Pu Reservoir was established based on the SWAT (Soil and Water Assessment Tool) model. The model was adjusted to analyse the temporal-spatial distribution patterns of total nitrogen (TN) and total phosphorus (TP). The results showed that the loss of TN and TP in the reservoir watershed were related to precipitation in flood season. And the annual changes showed an "M" shape. It was found that the contribution of loss of TN and TP accounted for $84.5 \%$ and $85.3 \%$ in high flow years, and for $70.3 \%$ and $69.7 \%$ in low flow years, respectively. The contributions in normal flow years were $62.9 \%$ and $63.3 \%$, respectively. The TN and TP mainly arise from Wangtan town, Gulai town, and Wangyuan town, etc. In addition, it was found that the source of TN and TP showed consistency in space.
\end{abstract}

Key words SWAT model; non-point pollution; temporal-spatial distribution; Tang Pu Reservoir

\section{INTRODUCTION}

Pollution of water can be divided into point source pollution and non-point source pollution (Cao et al., 2003). Point source pollution is a concentration of various wastewater discharges. The sources of non-point source pollution are more extensive (Gassman et al. 2007; Jin et al. (2012). Dissolved solid pollutants from the non-specific locations feed into the receiving waterbody, causing eutrophication or other forms of contamination, through runoff processes by fluviraption of precipitation or snowmelt (Saleh et al. 2000). These pollutants were used in agricultural production, and include large amounts of nitrogen, phosphorus, pesticides, heavy metals, and herbicides, etc. (Samira et al. 2010; Pionke et al. 1999). Non-point source pollution from fields was the most prominent.

Non-point source pollution has the characteristics of random occurrence, lagged effect and complex impact factor, thus leading to complexity and difficulty of non-point source pollution monitoring and treatment (Young et al. 1994). As the most widely-used model nowadays, SWAT (Soil Water Assessment Tool) is a distributed watershed-scale hydrological model. There are many successful applications in the fields of water resources and the environment.

Bulut et al. investigated the effects of fertilization rates of phosphorus (P) transport and phosphorus loading in lakes (Panagopoulos et al. 2011). Bouraoui et al. determined the main way of controlling the loss of nutrient using SWAT (Wan Chao and Zhang Sicong 2003). Domestic scholars like Fan Lili et al. simulated the agricultural non-point source pollution load in Daning River Watershed of Three Gorges Reservoir area using SWAT.

\section{OVERVIEW OF THE STUDY AREA}

Tang $\mathrm{Pu}$ Reservoir is located in southeast of the Kuaiji mountains, in the hilly area of east ZheJiang Province. The drainage area of the reservoir is $460 \mathrm{~km}^{2}$, the surface area is $14 \mathrm{~km}^{2}$, total storage of the reservoir is 235 million $\mathrm{m}^{3}$, daily water supply capacity is 1 million $\mathrm{m}^{3}$ day. The first-grade source protection zones is $52 \mathrm{~km}^{2}$. The second-grade source protection zones is $408 \mathrm{~km}^{2}$, including Shaoxing County and six towns in Sheng Zhou City (Fig. 1). Tang Pu Reservoir basin is shown in Fig. 1. 

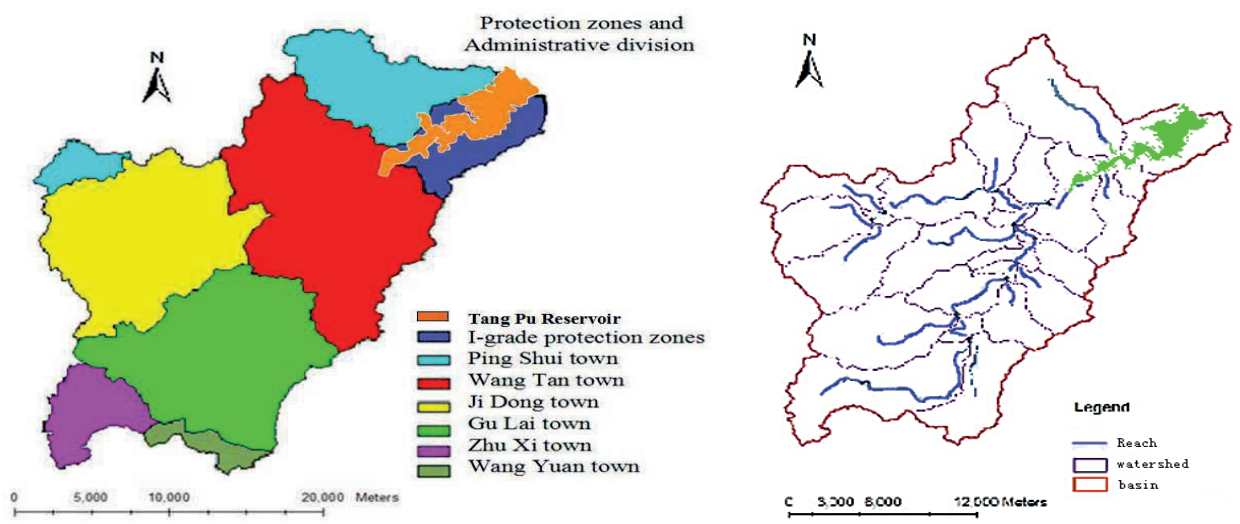

Fig. 1 (a) Drainage basin protection zone and administrative region; (b) sketch map of drainage basin.

\section{DATA AND METHODOLOGY}

\subsection{Spatial data}

Spatial data used in this study include digital elevation model (DEM data), land use and soil type information. DEM data, which is $30 \mathrm{~m} \times 30 \mathrm{~m}$ grid chart, comes from International Science Data Services Platform. Land use information comes from the Land Resources Bureau in Shaoxing. It is a shape file with a ratio of 1:50 000. The total area is $458.2 \mathrm{~km}^{2}$, of which forest accounts for most, $68.18 \%$, of the total area. The second land use was garden, accounting for $15.29 \%$ of the total area. Soil type information comes from the Geographic Institute of CAS. It is a shape file with the ratio of 1:100,000.The proportion of various types of soil in the basin were shown in Table 1.

Table 1 The area of different soil types in the basin.

\begin{tabular}{llcc}
\hline Code & Name & Area $\left(\mathrm{km}^{2}\right)$ & $\%$ \\
\hline 1 & Acid purple soil & 12.50 & 2.73 \\
2 & Meadow soil & 2.82 & 0.62 \\
3 & Skeleton soil & 25.82 & 5.64 \\
4 & Yellow soil & 39.78 & 8.68 \\
5 & Red soil & 351.09 & 76.63 \\
6 & Yellow brown soil & 26.18 & 5.71 \\
\hline
\end{tabular}

\subsection{Division of sub-watershed and HRU}

The threshold value for dividing the sub-watershed in this study was 1000 ha. Tang Pu Reservoir dam site was chosen as the basin export. The study area was divided into 27 sub-watersheds. Division into HRUs was based on a combination of different land use, soil type and slope information. According to the actual situation of the basin, the threshold value of land use area was $5 \%$, the threshold value of soil type was $5 \%$, and the threshold value of slope was $5 \%$. Eventually, 27 sub-watershed were divided into 288 HRUs.

\subsection{Calibration and verification of parameters}

The observed data of flow, total nitrogen (TN) and total phosphorus (TP) from 2002 to 2008 were used for model calibration, and the data from 2009 to 2011 were used for model validation. The LH-OAT method was used to make a sensitivity analysis of model. The results of the corrected parameters were shown on Table 2.

Table 2 The correction parameters threshold of SWAT model.

\begin{tabular}{llllllllll}
\hline Parameters & CN2 & ESCO & SOL_AWC & KUSLE $_{\text {US }}$ & CUSLE $_{\text {U }}$ & SP $_{\text {CON }}$ & SP $_{\text {EXP }}$ & NPERCO & PPERCO \\
Results & 67 & 0.79 & 0.02 & 0.6 & 0.018 & 0.008 & 1.4 & 1 & 12 \\
\hline
\end{tabular}


The relative prediction errors ( $\mathrm{Re}$ ) between simulated values and measured values was less than $15 \%$, the coefficient of determination $\left(\mathrm{R}^{2}\right)$ was more than 0.6 and the Nash-Sutcliffe coefficient was more than 0.5 ( $\mathrm{E}_{\mathrm{ns}}$; Table 3 ). It suggested that the model was more optimum to simulate the temporal-spatial distribution patterns of non-point pollution. After calibrating the model parameters, the data series from 2009 to 2011 were used for validating the model. The measured result and simulation results of flow/TN/TP in the calibration period and the validation period are shown as Figs 2-4.

Table 3 Results: TN is total nitrogen; TP is total phosphorus.

\begin{tabular}{lllllll}
\hline & \multicolumn{2}{l}{ Calibration period } & \multicolumn{4}{c}{ Validation period } \\
& $\mathrm{Re}$ & $\mathrm{R}^{2}$ & $\mathrm{E}_{\mathrm{ns}}$ & $\mathrm{Re}$ & $\mathrm{R}^{2}$ & $\mathrm{E}_{\mathrm{ns}}$ \\
\hline Flow & 18.99 & 0.61 & 0.52 & 9.35 & 0.83 & 0.81 \\
TN & 3.03 & 0.63 & 0.55 & 12.5 & 0.69 & 0.64 \\
$\mathrm{TP}$ & 4.2 & 0.68 & 0.64 & 9.8 & 0.71 & 0.65 \\
\hline
\end{tabular}

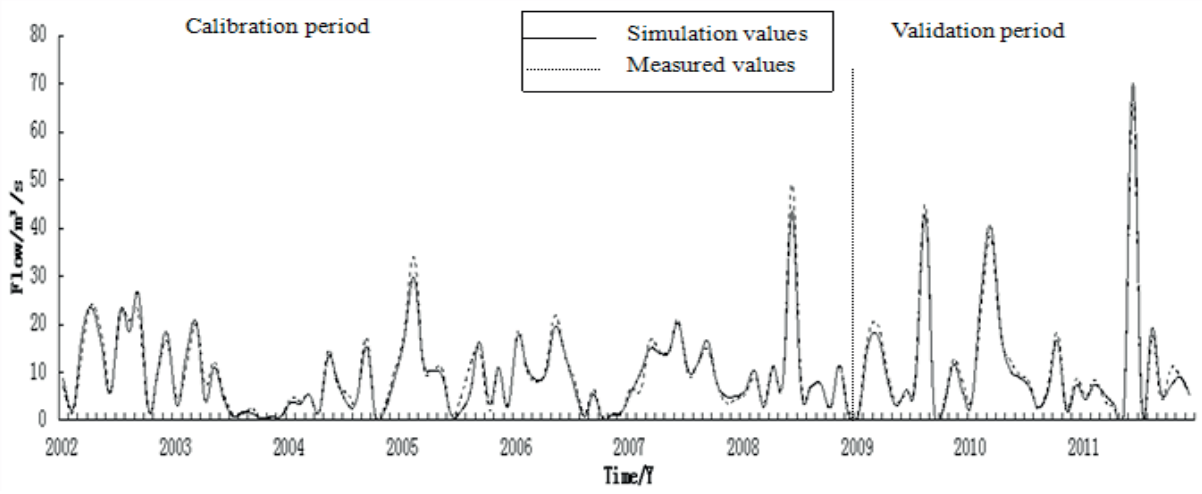

Fig. 2 Simulated and observed results of flow in calibration period and validation period.

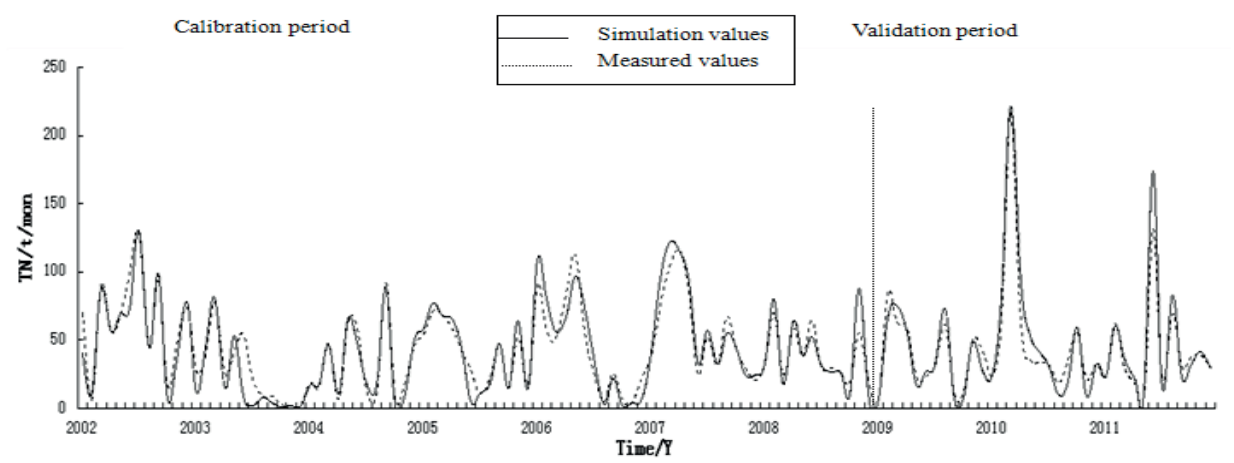

Fig. 3 Simulated and observed results of TN in calibration period and validation period.

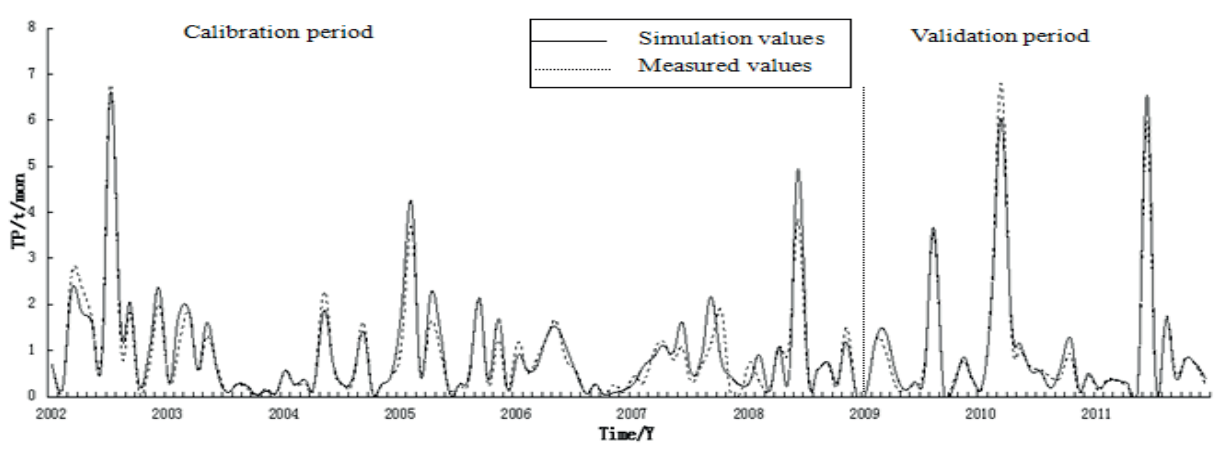

Fig. 4 Simulated and observed results of TP in calibration period and validation period. 


\section{TEMPORAL DISTRIBUTION OF NON-POINT SOURCE POLLUTION LOAD}

The pollution capacities of the non-point source in three typical hydrologic years for Tang $\mathrm{Pu}$ Reservoir were calculated with SWAT (Table 4). The TN and TP contents differed in different typical years. In the normal flow year (2006), the TN and TP contents were $47.9 \mathrm{t}$ and $6.1 \mathrm{t}$, respectively, which were lower than that in high flow year (2002) and low flow year (2003). The results suggest that there is a close relationship between the non-point source pollution by TN and TP and precipitation.

Table 4 The simulation result of non-point source pollution in different typical hydrologic years.

\begin{tabular}{llrr}
\hline Hydrological year & Precipitation $(\mathrm{mm})$ & $\mathrm{TN}(\mathrm{t})$ & $\mathrm{TP}(\mathrm{t})$ \\
\hline High flow year(2002) & 1695 & 266.4 & 33.0 \\
Normal flow year (2003) & 1240 & 47.9 & 6.1 \\
Low flow year(2006) & 879 & 134.2 & 16.3 \\
\hline
\end{tabular}
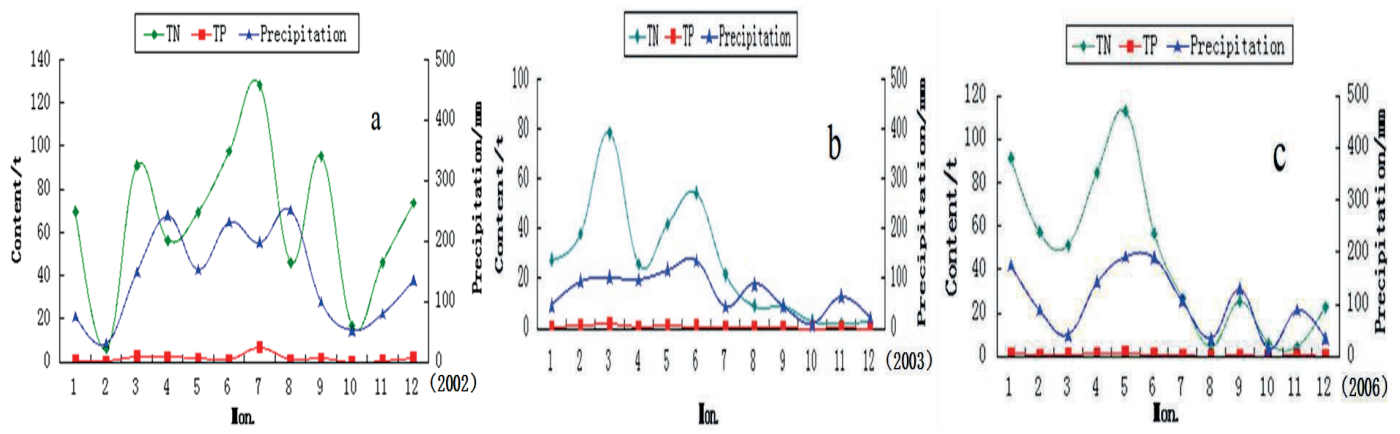

Fig. 5 The monthly distribution of precipitation and non-point source pollution.

As can be seen in Fig. 5(a), the rainfall capacity, TN, and TP contents of high flow year (2002) were concentrated in the flood season (March to September). In the flood season, the rainfall capacity was $72.28 \%$ of the whole year capacity, and the TN and TP contents were $84.45 \%$ and $85.38 \%$ of the whole year, respectively.

The rainfall capacity of low flow year (2003) was only $9 \mathrm{~mm}$ in October (Fig. 6(b)). The pollution capacities were inconsistent with the simulation value. In the flood period (April to September), the peak values of rainfall capacity were mainly distributed in March, June, August, and November with the average value of $72.74 \%$ for the whole year, and the TN and TP contents were $70.30 \%$ and $69.67 \%$, respectively.

In a normal flow year (2006, Fig. 6(c)), high rainfall was observed in January and November. The contents of pollution and sediment were also increased in January and November due to the increased rainfall capacity. It was calculated that the rainfall capacity, TN and TP contents were $64.18 \%, 62.97 \%$, and $63.30 \%$ in the flood season, respectively.

Non-point source pollution was mainly observed in the flood season, which was produced by rainfall-runoff processes especially in the main rainfall season. Positive correlation was found among the rainfall capacity, runoff volume, and sediment volume. High amounts of surface runoff lead to large quantities of sediment as well as non-point pollution. It was shown that both sediment and pollution were produced in high amounts in the more rainy months. This law was also suitable for the production of pollutant.

\section{SPATIAL DISTRIBUTION OF NON-POINT SOURCE POLLUTION LOAD}

The production of non-point source pollution load was strongly associated with spatiality, which has a close relationship with the rainfall capacity, soil characteristic, soil utilization situation, and topography of the given area. The area which produces non-point source pollution can be identified by the distribution of TN and TP contents of the Tang Pu Reservoir in different years. 


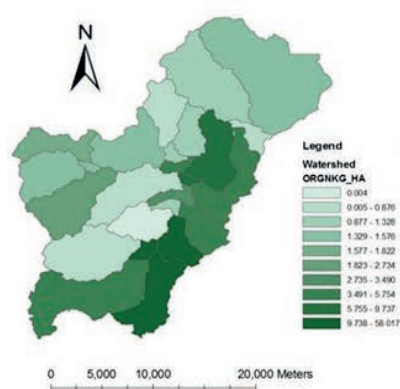

(a) High flow year (2002)

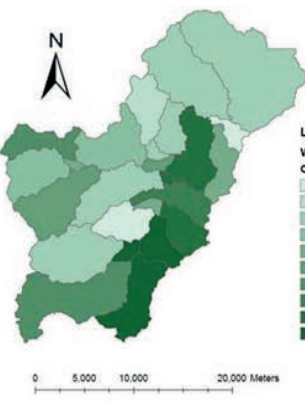

(b) Low flow year (2003)

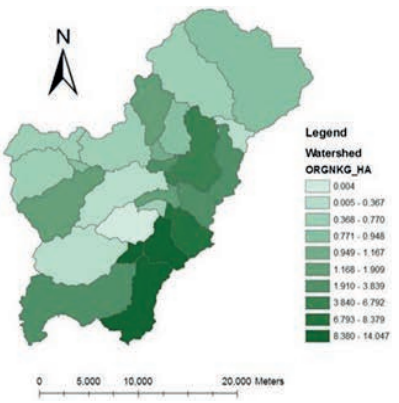

(c) Normal flow year (2006)

Fig. 6 The distribution of $\mathrm{TN}(\mathrm{kg} / / \mathrm{ha})$.

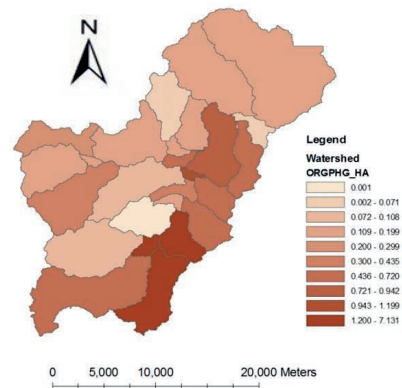

(a) High flow year (2002)

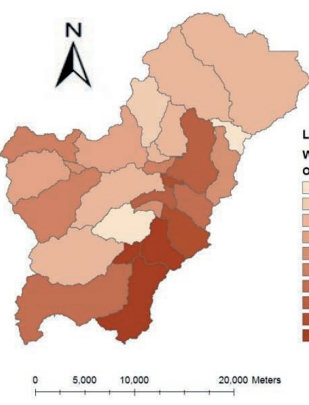

(b) Low flow year (2003)

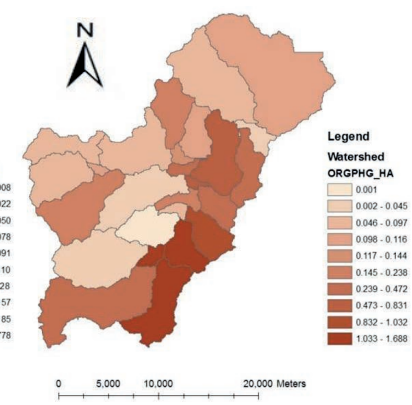

(c) Normal flow year (2006)

Fig. 7 The distribution of TP $(\mathrm{kg} / / \mathrm{ha})$.

As can be seen from Figs 6 and 7, the mainly pollutants of TN and TP were located in the south and east parts of the basin of Tang Pu Reservoir. According to analysis of the soil type, landuse map, and topographic data, the main soil types of the polluted basin were yellow soil and yellow brown soil, which are easily eroded. Because of the high proportion of agricultural land, the loads of pollution of TN and TP in the area were increased. In addition, a large population lives in the east and north of the basin, and the sewage produced was treated inappropriately, leading to additional pollutant content.

\section{CONCLUSION AND SUGGESTIONS}

The non-point source pollution load of Tang Pu reservoir watershed was distributed unevenly in districts, years and months, but was mainly produced in the flood season (April to September). During this period, much non-point pollution was carried into Tang Pu Reservoir by runoff.

In different typical hydrologic years, the annual change of non-point source pollution load was obvious, due to the difference of precipitation. The spatial distribution characteristic of the nonpoint source pollution load was high in the south and east of Tang Pu Reservoir watershed. This was because the widely distributed yellow and yellow brown soils are easily eroded in these areas. Furthermore, there is much agricultural land which further increase the pollution load in the south and east of Tang Pu watershed.

\section{REFERENCES}

Cao, W.Z. et al. (2003) Nutrient loss from an agricultural catchment and soil landscape modeling in southeast China. Bulletin of Environmental Contamination and Toxicology J. 71, 761-167

Gassman, P.W. et al. (2007) The soil and water assessment tool: Historical development, application, and future research directions. Transaction of the ASABE 50(4), 1211-1250.

Jin, J. et al. (2012) Influence of rainfall run-off in hydrologic process on non-point pollution. Agricultural Science \& Technology 13(2), 380-383, 444.

Panagopoulos, Y. et al. (2011) SWAT parameterization for the identification of critical diffuse pollution source areas under data limitations.Ecological Modeling 222(19), 3500-3512.

Pionke, H.B. et al. (1999) Seasonal flow, nutrient concentrations and loading patterns in stream flow draining an agricultural hill-land watershed. Journal of Hydrology 220, 62-73. 
Saleh, A. et al. (2000) Application of SWAT for the Upper North Bosque Watershed. Transactions of the ASAE. 43(5), 1077-1087. Samira, A. et al. (2010) Application of SWAT model to investigate nitrate leaching in Hamadan -Bahar Watershed, Iran. Agriculture, Ecosystem \& Environment. 139(4), 675-688.

Wan Chao and Zhang Sicong. (2003) Calculation of non-point source pollution loading for the Panjiakou reservoir based on GIS. Journal of Hydroelectric Engineering 2, 62-68.

Young, R.A. et al. (1994) Agricultural Non-Point Source Pollution Model. AGNPS User's Guide. 